\title{
Research on Evaluation for Operating Benefit of Electricity Retail Companies of Power Grid Based on Improved TOPSIS Method
}

\author{
Si $\mathrm{Li}^{1, \mathrm{a}^{*}}$ and Dongxiao Niu${ }^{1, \mathrm{~b}}$ \\ ${ }^{1}$ School of Economics and Management, North China Electric Power University, Changping, Beijing, \\ China \\ alis@ncepu.edu.cn, bniudx@ncepu.edu.cn \\ * The corresponding author
}

Keywords: Electricity retail companies of power grid; Operating benefit; Comprehensive evaluation; Improved TOPSIS method

\begin{abstract}
Now China is undergoing the electricity system reform and numerous electricity retail companies established by power grid participate in market competition. Evaluation for operating benefit can reflect whether the electricity retail companies of power grid have achieved healthy development in the sales side. Taking multidimensional factors into consideration, a set of scientific operating benefit evaluation indicator system and a comprehensive evaluation model based on the improved TOPSIS method is constructed in this paper. Applying this model to the evaluation for operating benefit of electricity retail companies of power grid, which is of great significance to the management and rational design of future operating development modes of electricity retail companies of power grid.
\end{abstract}

\section{Introduction}

The operating benefit of an enterprise should be comprehensively considered from various aspects, including technology production, financial status, innovation capability, etc., and the unilateral research will hardly make an effective assessment of the overall development of the company. Reference [1] measured the operating benefit from profitability, asset operation, debt repayment and development of the company and applied Factor Analysis (FA) to score the evaluation indicators. Reference [2] carried out a research on environmental protection companies, and a comprehensive evaluation method based on the combination of principal factors and cluster analysis was proposed innovatively.

Industry characteristics can have a certain impact on the evaluation for operating efficiency of enterprises. With the advancement of electricity marketization, the power grid enterprises are no longer traditional electricity suppliers. Instead, the nature of their services and social responsibility are increasingly valued, which is also reflected in the current studies on the evaluation of power grid companies. Reference [3] outlined the financial quality of enterprises and analyzed the financial quality of power grid companies, which helps managers to strengthen the assessment and management. Reference [4] took the power grid companies as the research object and constructed the operating risk indicator system from three aspects, including production operation, information security and power dispatch. Meanwhile, the reference combined the matter-element extension model with dynamic management to assess the operating risk of enterprises. Reference [5] adopted a method combining fuzzy comprehensive evaluation and weighted average synthesis operator to evaluate the energy management status of power grid companies. And reference [6] studied on the evaluation of the energy-saving and emission-reduction effects of power grid companies form the perspectives of the generation side, supply side and consumption side, effectively promoting the awareness of energy conservation of power grid companies and the development of energy-saving service industries. 


\section{Construction of the operating benefit evaluation indicator system and data pre-processing}

\section{Construction of the evaluation indicator system.}

In reference [7], there are six basic principles for the establishment of the indicator system, namely, the principles of purpose, completeness, operability, independence, dynamics and salience. Combining the above construction principles with the actual operating status of electricity retail companies under the background of the new reform, we considered the financial income, marketing, technology and production, internal management and social benefit to build the following operating benefit evaluation indicator system of electricity retail companies of power grid, and it is displayed in Table 1.

Table 1 The evaluation indicator system for operating benefit of electricity retail companies of power grid

\begin{tabular}{|c|c|c|}
\hline First-level indicator & Second-level indicator & Third-level indicator \\
\hline \multirow{9}{*}{ Financial income } & \multirow{3}{*}{ Basic operating capability } & Operating income \\
\hline & & Operating profit \\
\hline & & Return on investment \\
\hline & \multirow{3}{*}{ Solvency } & Assets and liabilities ratio \\
\hline & & Current ratio \\
\hline & & Quick ratio \\
\hline & \multirow{3}{*}{ Profitability } & Operating profit margin \\
\hline & & Sales margin \\
\hline & & Cost and expense margin \\
\hline \multirow{6}{*}{$\begin{array}{l}\text { Technology and } \\
\text { production }\end{array}$} & \multirow[t]{2}{*}{ Creativity } & $\begin{array}{c}\text { Innovation input-output ratio } \\
\text { Level of innovation consciousness }\end{array}$ \\
\hline & & Research input-output ratio \\
\hline & \multirow[t]{3}{*}{$\begin{array}{l}\text { Technological development } \\
\text { ability }\end{array}$} & $\begin{array}{c}\text { Proportion of highly educated } \\
\text { employees }\end{array}$ \\
\hline & & Application of information technology \\
\hline & & $\begin{array}{l}\text { Load forecast accuracy } \\
\text { Accuracy of electricity collection, } \\
\text { measurement and settlement }\end{array}$ \\
\hline & Technical service ability & $\begin{array}{c}\text { Perfection degree of integrated energy } \\
\text { service platform construction } \\
\text { Quality of core integrated energy } \\
\text { service }\end{array}$ \\
\hline \multirow{2}{*}{ Marketing } & \multirow{2}{*}{$\begin{array}{l}\text { Sales ability } \\
\text { Customer relationship } \\
\text { management ability }\end{array}$} & $\begin{array}{c}\text { Sales volume of electricity } \\
\text { Market share }\end{array}$ \\
\hline & & $\begin{array}{c}\text { Customer loyalty } \\
\text { Customer satisfaction }\end{array}$ \\
\hline \multirow{3}{*}{ Internal management } & Cultural cohesion & $\begin{array}{c}\text { Organization } \\
\text { Employee engagement } \\
\text { Institutional effectiveness }\end{array}$ \\
\hline & \multirow[b]{2}{*}{ Basic management ability } & Safety and quality management \\
\hline & & $\begin{array}{c}\text { Human resources management } \\
\text { Material Management } \\
\text { Business Management }\end{array}$ \\
\hline \multirow{3}{*}{ Social benefit } & \multirow{3}{*}{$\begin{array}{l}\text { Environmental coordination } \\
\text { ability } \\
\text { Provide employment ability } \\
\text { Brand communication ability }\end{array}$} & $\begin{array}{l}\text { Volume of pollutant reduction } \\
\text { Acceptance level of new energy }\end{array}$ \\
\hline & & Reemployment opportunities for employees \\
\hline & & $\begin{array}{c}\text { Brand image } \\
\text { Brand awareness }\end{array}$ \\
\hline
\end{tabular}

\section{Data pre-processing of Evaluation Indicators.}

Firstly, we should to classify the types of evaluation indicators. On the one hand, indicators can be often divided into two major categories, qualitative and quantitative indicators. On the other 
hand, those can also be divided into the benefit type, interval type and cost type. These three types of indicators are often converted into the same type in the evaluation process. In the operating benefit evaluation indicator system constructed above, 'assets and liabilities ratio' is an interval type indicator and others are benefit type indicators.

Before the standardization of indicators, the expert scoring method is applied to quantify qualitative indicators firstly. Assume that the number of invited authoritative experts is $M$, the score of the qualitative indicator $i$ of the $t$ th electricity retail companies of power grid, rated by the $k$ th expert independently is given by:

$$
S_{t i}=\frac{1}{M} \sum_{k=1}^{M} S_{t i}{ }^{k}
$$

Next, the conversion of interval type indicators into benefit ones is shown as follows:

$$
x_{i j}=\left\{\begin{array}{l}
1-\frac{q_{1}-x_{i j}^{0}}{\max \left\{q_{1}-d_{l}, d_{u}-q_{2}\right\}}, x<q_{1} \\
1-\frac{x_{i j}^{0}-q_{2}}{\max \left\{q_{1}-d_{l}, d_{u}-q_{2}\right\}}, x>q_{2}
\end{array}, x \in\left[q_{1}, q_{2}\right]\right.
$$

Where $x_{i j}^{0}$ is the original value, $\left[q_{1}, q_{2}\right]$ is the optimal interval, $d_{l}$ and $d_{u}$ are the allowable lower and upper limits of the evaluation indicators, respectively.

Then the standardization of all evaluation indicators is given by:

$$
x_{i j}^{*}=\frac{x_{i j}}{\sqrt{\sum_{i=1}^{m} x_{i j}^{2}}}, i=1,2, \cdots, m ; j=1,2, \cdots, n
$$

Where $m$ is the number of evaluated subjects, $n$ is the number of evaluation indicators.

\section{Empowerment of the Operating Benefit Evaluation Indicators.}

In this paper, we use entropy weight method to build a judgment matrix to empower the operating benefit evaluation indicators of electricity retail companies of power grid, which helps eliminate the subjectivity of weights and is more conducive to reflecting the orderliness of data information. The empowerment of indicators on the basis of entropy weight method is shown as follows:

(1) Construct the standardized judgment matrix

Assume that the total number of evaluated companies is $m$ and that of evaluation indicators is $n$. The standardized judgment matrix constructed from the above standardized data is given by:

$$
X^{*}=\left(x_{i j}^{*}\right)_{m \times n}, i=1,2, \cdots, m ; j=1,2, \cdots, n
$$

(2) Determine the information entropy of evaluation indicators

$$
\begin{aligned}
& H_{j}=-k \sum_{i=1}^{m} f_{i j} \ln f_{i j} \\
& f_{i j}=\frac{x_{i j}^{*}}{\sum_{i=1}^{m} x_{i j}^{*}} \\
& k=\frac{1}{\ln m}
\end{aligned}
$$

(3) Calculate weights of evaluation indicators 


$$
w_{j}=\frac{1-H_{j}}{\sum_{j=1}^{n}\left(1-H_{j}\right)}
$$

Where $0 \leq w_{j} \leq 1, \sum_{j=1}^{n} w_{j}=1$.

\section{Construction of the Evaluation Model for Operating Benefit of Electricity Retail Companies of Power Grid}

The references [8-10] pointed out that traditional TOPSIS method always had problems of reverse order in the evaluation of multi-indicators and multi-objects. The final sorting results may be changed due to the changes of positive and negative ideal solutions or the weights of evaluation indicators. Therefore, in this paper, the improved TOPSIS method is used for the evaluation of operating benefit to obtain closer evaluation results with actual operations, which provides a scientific and comprehensive guidance for the electricity retail companies of power grid to formulate the operation and development model in the future stage.

The process of evaluation based on the improved TOPSIS method is shown as follows:

(1) The weighted judgment matrix is given by:

$$
\begin{aligned}
& R=\left(r_{i j}\right)_{m \times n} \\
& r_{i j}=w_{j} \cdot x_{i j}^{*}, i=1,2, \cdots, m ; j=1,2, \cdots, n
\end{aligned}
$$

(2) The absolute ideal solutions are given by:

$$
\begin{aligned}
& X^{+}=\left(r_{1}^{+}, r_{2}^{+}, r_{3}^{+}, \cdots, r_{m}^{+}\right) \\
& X^{-}=\left(r_{1}^{-}, r_{2}^{-}, r_{3}^{-}, \cdots, r_{m}^{-}\right)
\end{aligned}
$$

In practical applications, where positive and negative ideal solutions are often set as follows: $X^{+}=(1,1, \cdots, 1)^{T}, \quad X^{-}=(0,0, \cdots, 0)^{T}$.

(3) The Euclidean distance between the evaluated objects and absolute ideal solutions is given by:

$$
\begin{aligned}
& D^{+}=\sqrt{\sum_{j=1}^{n} w_{j}\left(X^{+}-x_{i j}^{*}\right)^{2}} \\
& D^{-}=\sqrt{\sum_{j=1}^{n} w_{j}\left(X^{-}-x_{i j}^{*}\right)^{2}}
\end{aligned}
$$

(4) The relative proximity of each evaluated object is given by:

$$
C_{i}=\frac{D^{-}}{D^{+}+D^{-}}
$$

(5) Sorting results of evaluated objects are obtained according to the following rule:

The value of relative proximity is equivalent to the evaluation scores. Electricity retail companies are ranked based on the value of $C_{i}$, where the larger the value of $C_{i}$, the better the operating benefit of the corresponding company.

\section{Example Analysis}

Assume that the number of evaluated electricity retail companies of power grid is 20 , and the selected operating benefit evaluation indicators are shown in Table 1. In the example analysis, we 
have the improved TOPSIS method to conduct the evaluation for operating benefit of the electricity retail companies of power grid.

(1) Preprocessing of original data of operating benefit evaluation indicators

Firstly, 8 experts are invited to complete the quantification process of qualitative indicators by Eq. 1. Secondly, indicators are converted into the benefit ones by Eq. 2. Finally, all the operating benefit indicators are standardized by Eq. 3 .

(2) Empowerment of operating benefit evaluation indicators

Following Eq. 4 Eq. 8 to process the standardized judgment matrix, and the weights of operating benefit evaluation indicators are $(0.0097,0.0115,0.0279,0.0554,0.1360,0.1456,0.0760$, $0.2341,0.0040,0.0100,0.0114,0.0387,0.0773,0.0093,0.0107,0.0000,0.0000$, $0.0000,0.0432,0.0349,0.0040,0.0039,0.0014,0.0018,0.0004,0.0012,0.0007$, $0.0060,0.0031,0.0061,0.0060)$, respectively.

(3) Calculation of the Euclidean distance between companies and the absolute ideal solutions

The values of positive and negative absolute ideal solutions are given by: $X^{+}=(1,1, \cdots, 1)^{T}$, $X^{-}=(0,0, \cdots, 0)^{T}$. And the Euclidean distance is calculated by Eq. 13 Eq. 14.

(4) Calculation of the relative proximity between companies and the absolute ideal solutions

Following Eq. 15 to obtain the relative proximity and the results are $(0.2581,0.2402$, $0.1859,0.2574,0.2613,0.1871,0.1796,0.1603,0.2082,0.1893,0.2469,0.2723$, $0.2432,0.1871,0.2373,0.2148,0.2385,0.1872,0.1617,0.2756)$. The relative proximity determined by the improved TOPSIS method is the evaluation scores of each electricity retail companies of power grid, the lager value corresponds to better operating benefit. Therefore, we rank these 20 electricity retail companies of power grid according to the relative proximity, the results are displayed in Fig. 1.

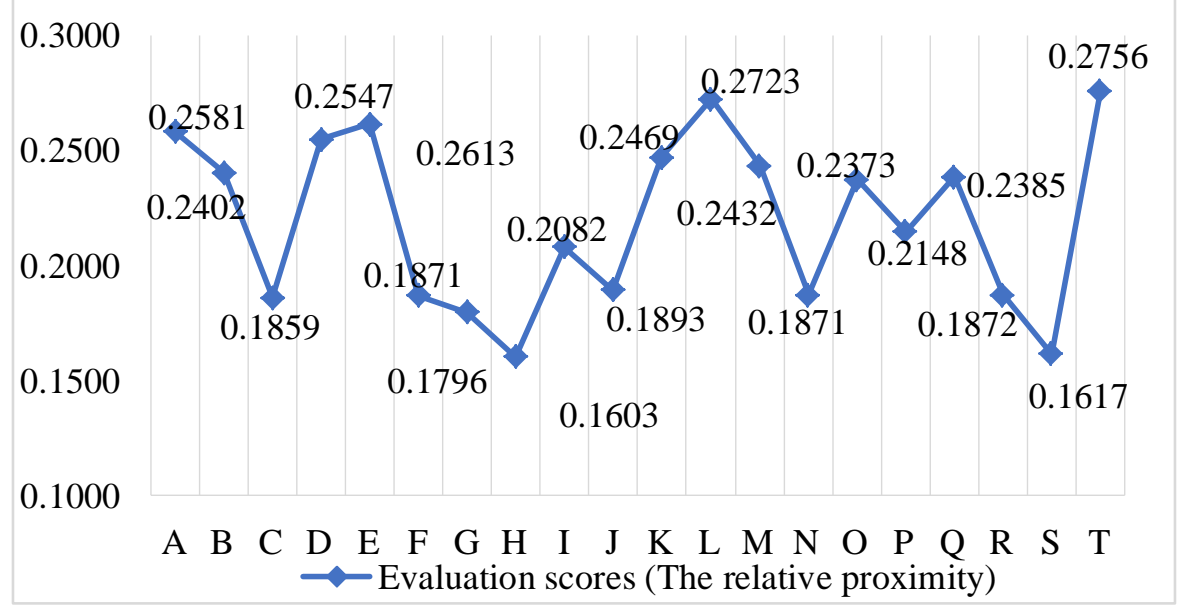

Figure 1. Finite Evaluation scores of the 20 electricity retailers of power grid

One can observe that conduct the evaluation for operating benefit of electricity retail companies of power grid based on the improved TOPSIS method, the results reflect the electricity retail companies of power grid $\mathrm{T}$ has the best operating benefit and $\mathrm{H}$ has the worst one.

\section{Summary}

In this paper, we considered the background of a new electricity system reform and selected reasonable indicators to build an operating benefit evaluation indicator system for electricity retail companies of power grid. Then we have improved traditional TOPSIS method to eliminate the reverse order problems in the multi-attribute decision-making. Meanwhile, a comprehensive evaluation for operating benefit of electricity retail companies of power grid was conducted on the basis of the improved TOPSIS method, which provides a decision basis for a more reasonable operation and development mode and realizes the sustainable development in the future market for 
the electricity retail companies of power grid.

\section{References}

[1] B.L. Cao and Z.M. Y: J. Liaoning University Technology Social \& Science, Vol. 2 (2015), p.30-32. (In Chinese)

[2] Y.Q. Li and X. Y. Zhang: Business, Vol. 37 (2015), p.206-207. (In Chinese)

[3] N.Y. Su: Economic \& Trade Update, Vol. 11 (2011), p.188-189. (In Chinese)

[4] Z.P. Shi, T.H. Shan, W.F. Liu and X.P. Zhang: Power System Technology, Vol. 39 (2015), P.3233-3239. (In Chinese)

[5] X.Q. Xue, X. Ye and W. Hong: Energy Conservation Technology, Vol. 33 (2015), p.546-549. (In Chinese)

[6] Q.Y. Liu. Research on comprehensive evaluation of contribution effect of energy saving and emission reduction for power grid enterprises (MS., North China Electric Power University, China 2012). (In Chinese)

[7] Z.L. Peng, A.P. Zhang, S.F. Wang and Y. Bai: Science Research Management, Vol. s1 (2017), p.209-215. (In Chinese)

[8] W.J. Wang, D. Tong and X.X. Lu: Manager Journal, Vol. 29 (2015), p.1-2. (In Chinese)

[9] S.J. Feng. The research on the methods of combination weighting and TOPSIS in the multiple attribute decision making (MS., Jiangsu University of Science and Technology, China 2016). (In Chinese)

[10] W.F. Lu and H.X. Tang. Statistics \& Decision, Vol. 19 (2012), p. 38-40. (In Chinese) 